\title{
TRES PUENTES, TRES CIUDADES
}

\author{
(THREE BRIDGES, THREE TOWNS) \\ José A. Fernández Ordoñez, Dr. Ingeniero de Caminos \\ ESPAÑA
}

Fecha de recepción: 29-IV-98

560-32

\author{
RESUMEN \\ Constituye el presente articulo una descripción de las \\ diferentes etapas por las que han pasado los proyectos de \\ construcción de tres puentes emblemáticos, además, de otras \\ tantas ciudades del mundo.
}

SUMMARY

This paper contains a description of the process the construction projects of three bridges went through. Besides, these three bridges are emblematic of as many towns in different parts of the world.

\section{VENECIA. EL PUENTE DE RIALTO}

Este conjunto de 200 islotes que llamamos Venecia, agrupados en el centro de una laguna de $50 \mathrm{~km}$ de longitud por $10 \mathrm{~km}$ de anchura media, separada del mar por estrechas y alargadas lenguas arenosas, ha sido, desde hace más de mil años, un centro productor de puentes de todo tipo.

La necesidad de comunicación de sus habitantes forzó el paso sobre los pequeños canales, al principio por medio de puentes de barcas, luego con pequeñas estructuras de madera y, más tarde, con bóvedas de piedra y ladrillo. Los problemas constructivos más agudos se presentaban siempre en las cimentaciones. El terreno de la laguna es un depósito aluvial incapaz de resistir cargas concentradas, por lo que la utilización de pilotes hincados de madera era inexcusable.

El Gran Canal, con sus $70 \mathrm{~m}$ de anchura media, constituía una barrera infranqueable que dividía Venecia en dos zonas aisladas. La ausencia de un enlace fijo y perdurable entre ambas partes de esta gran vía de agua en forma de $\mathrm{S}$, lo que para Hogarth era la línea de la belleza, obstaculizaba el crecimiento armónico del conjunto urbano.

Entre los centenares de puentes de Venecia sobre toda clase de canales, ninguno presentaba la dificultad que suponía volar sobre el Gran Canal. Al borde del islote de Rivo Alto se encontraba su único y fuerte estrechamiento, aproximadamente en el centro de sus $4 \mathrm{~km}$ de su longitud, constituyendo el lugar idóneo para la conexión entre ambas márgenes, empleado como paso transversal sobre el Gran Canal probablemente desde tiempo inmemorial, y que originó allí la formación del futuro centro comercial de la ciudad.

Desde el siglo XII existía, allí mismo, un puente de barcas llamado Quartarolo o Puente Moneta, por la pequeña moneda que se cobraba como peaje. En este mismo lugar se construyó, a mediados del siglo XV, el famoso puente cubierto de madera -levadizo en su parte central- que con tanta fidelidad reprodujo en 1500 Jacopo de Barbari en su enorme grabado sobre madera de toda la ciudad, en perspectiva caballera, que se conserva en el Museo Correr. Se trata del mismo puente que inmortalizó en 1494 Vittore Carpaccio en su pintura "El Patriarca de grado libera un leproso", conservada en la Galería de la Academia. No hay duda que éste era un lugar ciertamente especial, donde además se celebraba anualmente la ceremonia de esponsales de Venecia con el mar, lanzando al agua el anillo consagrado. En el cuadro se observa -en contra de la creencia común- que el puente sólo estaba cubierto en sus zonas de tiendas y se aprecia con claridad la estructura en celosía de la pila de madera de alerce, esa especie de cedro 
de troncos derechos y fuertes de color verdegay que, aparte de suministrar una estupenda madera para las construcciones hidráulicas venecianas, proveía de corteza para curtir pieles y de la odorífera trementina, como disolvente de pinturas.

En 1512, el año en que nació en Venecia Antonio Da Ponte -futuro constructor del actual puente de Rialto-, un gran incendio dañó todo el barrio y el propio puente de madera. Desde entonces hasta 1588 , en que comenzaron las obras del nuevo puente, el Senado anduvo buscando soluciones definitivas invitando a célebres arquitectos y convocando concursos. Dos datos de partida eran indiscutibles: el futuro puente debería construirse en piedra y se financiaría con las tiendas que allí se instalasen.

Fra Giovanni Giocondo, proyectista del puente de Nôtre Dame en París, fue el primero en proponer una solución. En 1529 Miguel Ángel preparó un diseño que se ha perdido. Vignola hizo también otra propuesta. Tanto Sansovino como Scamozzi presentaron soluciones, ambas con tres vanos.

Pero las propuestas básicas -de conceptos opuestos- sobre las que el Senado tuvo que decidir, fueron la de Palladio y la de Da Ponte. Conocemos muy bien la de Palladio, ya que la expone con detalle en su libro Terzo, junto con otros puentes de madera en arco y celosía muy interesantes. Más que un puente, Palladio proyecta un verdadero monumento, que podría considerarse como el modelo de los grandes Puentes triunfales que tan en boga estuvieron gracias a las Escuelas y Academias de Bellas Artes de Francia e Inglaterra.
Aparentemente inspirado en los puentes urbanos romanos, debido sobre todo a su rasante horizontal, sus tres vanos y sus nichos clásicos a la manera de Rímini, colmado de enormes vestíbulos y galerías con columnas y frontones, el de Palladio tenía 72 tiendas en 3 calles, con una anchura que suponía el $60 \%$ de su longitud total. A pesar de los autoelogios que Palladio se dispensó en su libro -cosa no frecuente en él y que demuestra el enorme interés que tenía en llevar a cabo su construcción- y de su gran prestigio e influencia, no consiguió convencer al Senado.

Las ventajas de la solución -mucho más sencilla y técnicaque presentó Da Ponte eran incontestables. En efecto, su puente tenía una rasante quebrada, lo que eliminaba las escaleras en los accesos y permitía no tocar las edificaciones aledañas. Además, la creación de una sola bóveda escarzana, formada por un tercio de segmento de círculo de 85 pies de luz, con una esbeltez (relación luz/flecha) superior a 4, permitía un gálibo vertical superior en un $40 \%$ al de Palladio, al tiempo que eliminaba sus dos pilas intermedias, que ocupaban la cuarta parte del desagüe total, y permitía el paso franco de la gran embarcación de los dogos -el Bocentoro-, incluyendo los remos, lo que con la solución de Palladio no era posible. Para colmo, Antonio Da Ponte -que tenía 75 años cuando concurrió al concursopresentó una solución mucho más económica y de menor plazo constructivo, que se financiaba limitando las tiendas a dos filas, con una anchura de 66 pies.

Da Ponte resolvió magistralmente las cimentaciones de los estribos con un conjunto de 3 familias de miles de pilotes coronados con emparrillados de maderas de pino a tres niveles, garantizando, de este modo, la estabilidad de los

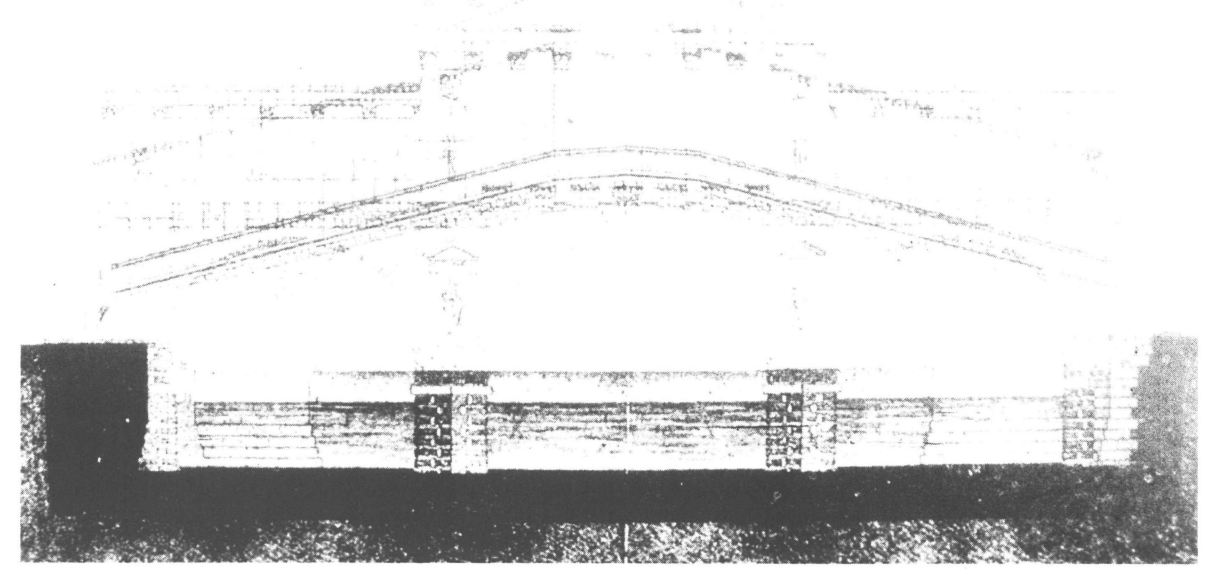

Figura 1.- Superposición de las soluciones de Andrea Palladio y Antonio da Ponte para el Puente de Rialto 


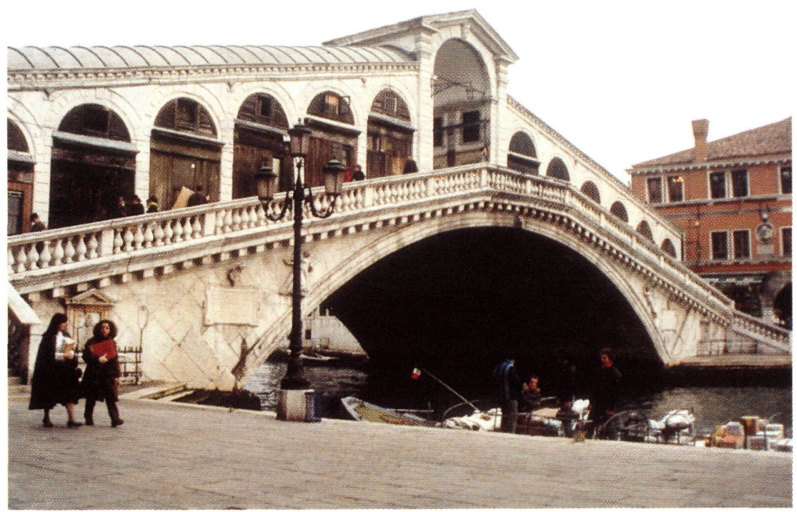

Figura 2.- El Puente de Rialto.

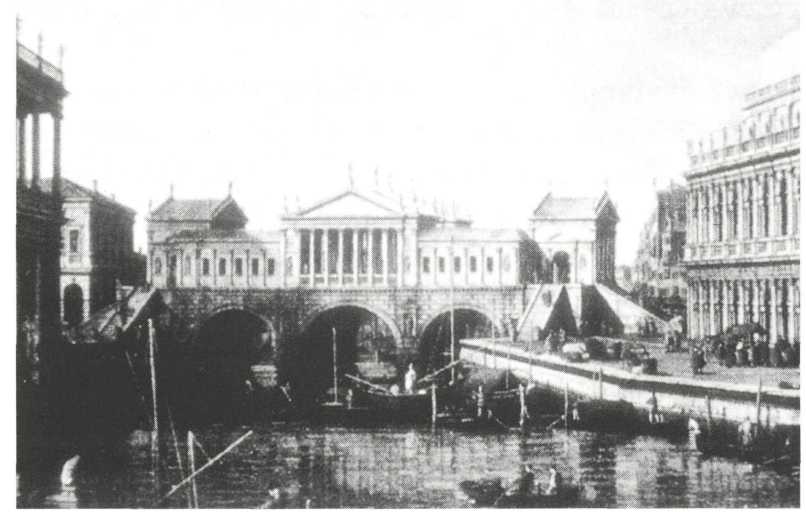

Figura 3.- Solución de Palladio para el Puente de Rialtu IOleo de Canaletto. galeria Nacional de Parma).

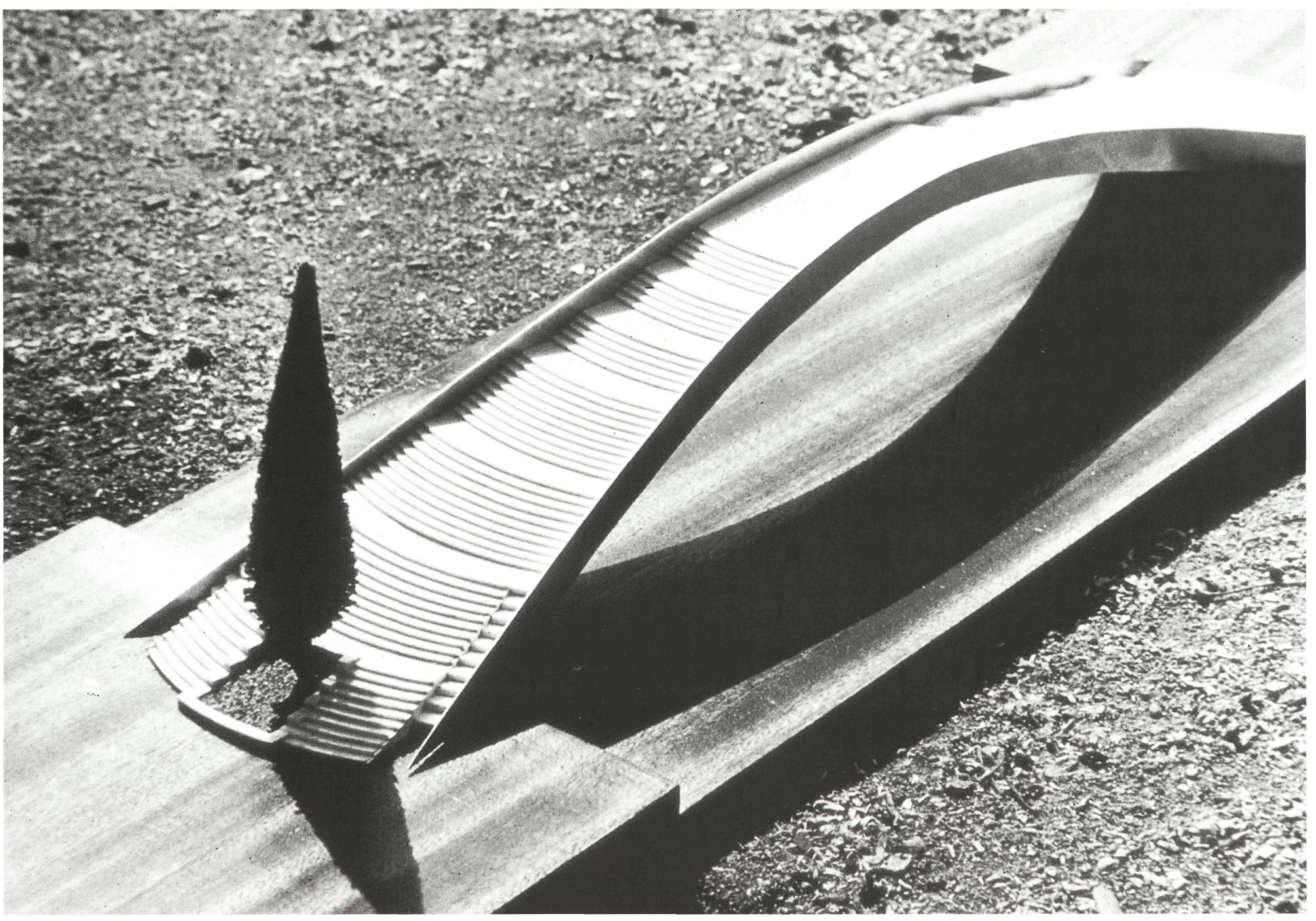

Figura 4. - Nuevo Puente de la Academia en Venecia (1985). Proyecto de los ingenieros JoséA. Fernández Ordónez y Julio Martinez Calzón y del arquitecto Salvador Tarragó.

edificios adyacentes -muy cercanos al Gran Canal-, algo en lo que Palladio ni había pensado. Arrancando sobre estas plataformas con rellenos triangulares de ladrillo con dovelas a base de juntas radiales, -lo que fue duramente criticado por Scamozzi que creía que debían ser horizontales-, se elevó hacia la clave por medio de los bien conocidos planos inclinados de las enjutas.

(c) Consejo Superior de Investigaciones Científicas Licencia Creative Commons 3.0 España (by-nc)
Con todo, a pesar de las grandes dificultades técnicas que Da Ponte tuvo que superar, apoyado, casi exclusivamente, en su intuición y en su gran sentido común, toda vez que los conocimientos de la época no daban para más, lo más complicado para él fueron los continuos informes técnicos insidiosos con que le atacaban -sobre todo los de un Scamozzi reconcomido de envidia- que llegaron a detener 
56

Informes de la Construcción, Vol. 50 n $456-457$ julio/agosto - septiembre/octubre 1998

las obras en junio de 1588 cuando se habían terminado de hincar todos los pilotes, a los cinco meses de su comienzo.

Bajo un montón de dudas y censuras seudotécnicas -nadie criticó, por ejemplo, que los pilotes se hincasen unos junto a otros sin dejar superficies de fricción-, surgía siempre, al final de estos escritos, la verdadera preocupación de sus oponentes que no era otra que la estética, con afirmaciones como "dos o tres arcos de medio punto hubieran sido más hermosos que uno rebajado".

Con su gran temple, con la claridad de sus argumentos, con ausencia de resentimiento y con una gran dignidad en sus réplicas, Da Ponte pudo sacar adelante su proyecto con algún pequeño cambio, que tuvo que hacer para que sus objetores quedasen satisfechos. Recién terminado el nuevo puente de Rialto, en 1591, un terremoto sacudió toda Venecia sin aparecer la menor fisura en toda su estructura.
Antonio Da Ponte nunca pretendió construir un monumento ni un simbolo; se planteó solamente resolver sobre el Gran Canal una conexión permanente, de piedra, que no fuera en el futuro afectada por incendios ni por terremotos, y que además resultase autofinanciable, fácil de conservar, económica y sencilla de construir en un breve plazo.

Da Ponte consiguió su objetivo y además -como regalo- la posteridad convirtió su puente en el símbolo de Venecia. En el Códice Marciano Italiano se dice: "El puente no es sólo un ornamento para la ciudad, sino una gran conveniencia para sus negocios. Por estas razones pienso que es la más bella estructura, no sólo de Venecia, sino de otras ciudades también... El puente permanecerá de pie eternamente junto a esta maravillosa y única ciudad". Y Ruskin, más tarde, en "Las Piedras de Venecia", escribe: "Muy noble en su simplicidad, en su proporción, en su fábrica, con sus piedras inclinadas en los estribos, digna de confianza, palpable y evidente a los ojos y al sentimiento". 


\section{NUEVA YORK. EL PUENTE DE BROOKLYN}

El East River es un río formado por la excavación de los glaciares entre dos islas, Manhattan y Long Island, donde se asentaban, respectivamente, a principios del siglo XIX las poblaciones de dos municipios independientes: Nueva York y Brooklyn. Desde entonces se deseaba superar esta barrera natural entre las dos ciudades con un enlace fijo lo que, en aquellos años, parecía una obra quimérica por la gran luz que había que salvar.

Un décimo de la población de Brooklyn cruzaba por ferry a diario el East River. En 1810 tenía 3.000 habitantes. A fin de siglo alcanzaba el millón de habitantes, creciendo más deprisa que Nueva York. Manhattan era rocosa, estéril y arenosa. Los granjeros se establecieron en Brooklyn y los comerciantes en Nueva York. Durante la década de los 40, Walt Whitman era uno de los que residía en Brooklyn y trabajaba en Manhattan, cruzando a diario el East River en un ferry cada vez más ineficaz. Whitman amaba tanto "las amplias colinas de Brooklyn como las calles de la isla de Manhattan".

Thomas Pope, un artesano y topógrafo neoyorquino, propuso, en fecha tan temprana como 1811, su fantasioso puente arco iris (rainbow brigde) para superar el East River. Se trataba de un arco delgadísimo de madera en cantilever, muy plano, con dos vigas de alma llena en voladizo, rigidizadas con diagonales: un puente por completo irrealizable. Pope construyó un modelo de $30 \mathrm{~m}$ y lo exhibió en Nueva York, pensando que podría aplicarlo hasta para $1.000 \mathrm{~m}$ de luz y que, por consiguiente, sería válido para los $500 \mathrm{~m}$ del East River. Con su puente -al que llama "totalidad perfecta", porque muestra la verdad y la ciencia frente a la ignorancia y la superstición-, Pope pensaba "romper los rudas y bárbaras cadenas de la tradición académica".

La aspiración de Pope era la de producir un puente con una "forma nacional", americano, genérico y universal, que pudiera aplicarse para vencer cualquiera de sus grandes ríos, sin necesidad de diseñarlo como los europeos para un lugar específico, utilizando "las mejores maderas de nuestros bosques".

Con su buena dosis de ingenuidad técnica, Pope respondía a una urgente necesidad que todos compartían: la creación de un grande y eficiente sistema de comunicaciones en el nuevo continente. Para Jefferson, la construcción de carreteras y canales era una misión fundamental del gobierno central: "Las fronteras entre los Estados de la Unión desaparecerán, sus intereses serán identificados, y su unión será cementada por nuevos lazos indestructibles". Esta visión utópica de la carretera tiene su expresión más conmovedora en Whitman: "La carretera está ante nosotros, expandiéndose a derecha e izquierda, hacia el aire libre, donde pueden concebirse todas las hazañas heroi- cas". Para Whitman, uniendo el Este tradicional con el nuevo Oeste, las carreteras nos devuelven a la naturaleza, al "temprano y primer paraíso de la razón ... y a las inocentes intuiciones". El Progreso, para él, es una vuelta al "oscuro e inpenetrable pasado". Con el futuro puente de Brooklyn, el continente estaría unido desde el Atlántico al Pacífico. El puente sería la señal de que la nación había superado la guerra civil y tomaba su verdadero camino: la dominación pacífica de la naturaleza.

Hay en nuestro Cerdá un tronco común con Whitman, una convic ción de que el campo debe urbanizarse y la ciudad ruralizarse, una visión utópica del valor humanizador y benefactor de las comunicaciones. Ni Whitman ni Cerdá veían conflicto entre los dos modos de vida ciudad y campo, en una progresiva transformación de la naturaleza. En esta línea progresista estaba también Emerson, quien pensaba que el ferrocarril llevaría los habitantes de la ciudad a colonizar el campo, aunque lo que sucedió fue que las gentes viajaron en dirección opuesta. Cerdá estaba convencido de que la extensión del ferrocarril contribuiría a la fraternidad universal y, Emerson, de que era "la varita mágica que despertaría con su poder las dormidas energías de la tierra y el agua". Thomas Ewbank pensaba que los ingenieros tenían "los futuros destinos del planeta en sus manos" y que la máquina de vapor era más épica que la Ilíada.

A este mundo llega desde Alemania, como un inmigrante más, el joven John August Roebling. Había nacido en 1806 en Mülhausen, una pequeña y tranquila ciudad alemana de comerciantes, graduándose en 1826 como ingeniero en el Politécnico de Berlín. Allí recibió enseñanzas técnicas, pero también las estéticas y filosóficas de Hegel, del que llegó a ser alumno predilecto y amigo personal. En 1831 , año en que muere Hegel, emigra a los Estados Unidos con un grupo de sus paisanos, estableciéndose como granjero cerca de Pittsburg, fundando un pueblo al que llamaron Germania, y luego, Saxonburg.

En un largo viaje de seis semanas hacia el Nuevo Mundo, escribe en su diario: "Nada puede ser llevado a cabo en Alemania con un ejército de funcionarios y consejer os que discuten cada asunto diez años, haciendo viajes, escribiendo largos informes, gastando más dinero en trabajos preliminares que el que costaría culminar la propia empresa". Se sentía fuertemente atraído por América, por sus enormes espacios disponibles, por su Constitución republicana, "la tierra del futuro, la tierra deseada por todos los que están cansados del histórico trastero de la vieja Europa", como había escuchado a su maestro Hegel.

En América, después de convencerse de su falta de capacidad y competencia para la vida de granjero, ingresa en 1837 en una compañía de canales. Nunca más labraría la tierra, pero como ingeniero conseguiría las cotas más altas, además de alcanzar esos sueños de autorrealización que 
tenía desde su juventud, "espiritualizar la naturaleza", según sus propias palabras. Su aportación técnica fundamental fue la de abrir el camino para el proyecto y puesta en práctica de los grandes puentes colgantes modernos.

Aunque el puente colgante existe desde la antigüedad en Oriente, fue la última de las formas básicas que apareció en Europa. Originalmente inventado en China hacia el siglo I a.c., la primera ilustración europea fue publicada por Faustus Verantius, a finales del siglo XVI.

El joven Roebling había realizado su tesis doctoral sobre un pequeño puente colgante de cadenas de hierro que vio en unas vacaciones de estudiante. Su obsesión por las estructuras suspendidas nunca le había abandonado. Trabajando en un canal, advirtió el método -usual en aquellos años- tan peligroso y antieconómico de arrastrar las barcazas sobre vagonetas por planos inclinados, por medio de cuerdas de cáñamo. Imaginó y puso en práctica, en 1840 , con la ayuda de sus vecinos de Saxonburg, la fabricación de un cable metálico enrrollando unos alambres de hierro sobre un alma de cáñamo o de hierro. Era tan flexible que podía acomodarse al cabrestante y mucho más resistente y duradero que los de cáñamo. Este sensacional invento, el cable metálico, le permitiría crear una industria familiar próspera, que todavía hoy dura, y su inmediata aplicación a los puentes colgantes. Hegel le había enseñado que el constructor transforma los materiales de indiferentes en sensibles.

En 1850 ya tenía en su haber seis estructuras suspendidas, y su prestigio como fabricante de cables metálicos y como ingeniero proyectista iba en aumento. Su negocio le permite una cómoda posibilidad de investigar y una independencia económica que los demás ingenieros civiles no tienen. Su resonante éxito -contra todos los pronósticos de los más famosos ingenieros- en el puente colgante para ferrocarril sobre las cataratas del Niágara en 1855 extiende su fama a Europa. "Si su puente tiene éxito, el mío es magnífico

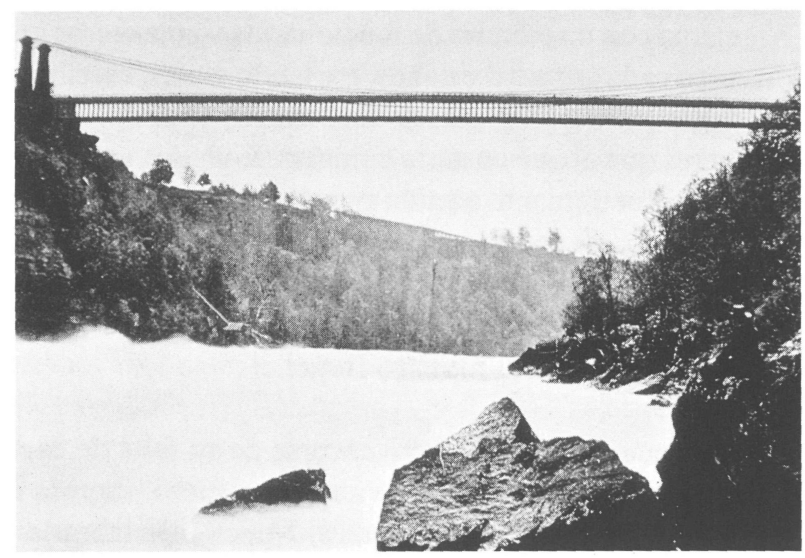

Figura 5.- Puente para ferrocarril y carretera sobre las cataratas del Niágara (J. A. Roebling, 1855). desatino", le había escrito el célebre Robert Stephenson, quien pensaba en la imposibilidad de realización de un gran puente colgante para ferrocarril y, de ahí, que Stephenson hubiese construido su puente Britannia en 1850 con enormes vigas cajón metálicas de sección rectangular hueca.

Después de construir el puente colgante de Cincinatti, con un nuevo récord mundial de $322 \mathrm{~m}$ de luz, Roebling afronta el puente sobre la barrera del East River, cuyo proyecto presenta sólo en tres meses, lo que significa que sabía muy bien lo que tenía que hacer. Roebling conocía aquel lugar desde hacía muchos años y le obsesionaba el reto físico. Como el propio puente, el entorno natural es una parte esencial de la apuesta técnica, ya que son las exigencias del lugar las que deben ser pensadas y vencidas. Es la base inflexible que soportará la estructura.

Construido entre 1869 y 1883 , el Puente de Brooklyn encarna "todo aquello por lo que la época se sentía justamente orgullosa -sus avances de ciencia, su habilidad en el manejo del hierro, el heroísmo personal frente a los peligrosos procesos industriales, su voluntad de emprender lo desconocido y que parecía imposible", tal y como señala Lewis Mumford.

Roebling quería algo más que una obra de ingeniería. Cuando presenta su proyecto, señala no sólo la magnitud de la obra, sino su carácter simbólico, así como la seguridad de que "será considerada con el rango de los monumentos nacionales", lo que no sucedió oficialmente hasta un siglo después. Roebling no piensa sólo en la estricta funcionalidad. Proyecta unas torres-pantalla de caliza y granito escogidísimos, de textura muy rugosa, horadadas por huecos ojivales -independientes de la función resistentemucho más altos de lo exigido por el gálibo de circulación, con tres contrafuertes con escalones retranqueados y una cornisa de coronación que oculta el paso de los cables principales y el anclaje de los atirantados. Asimismo,

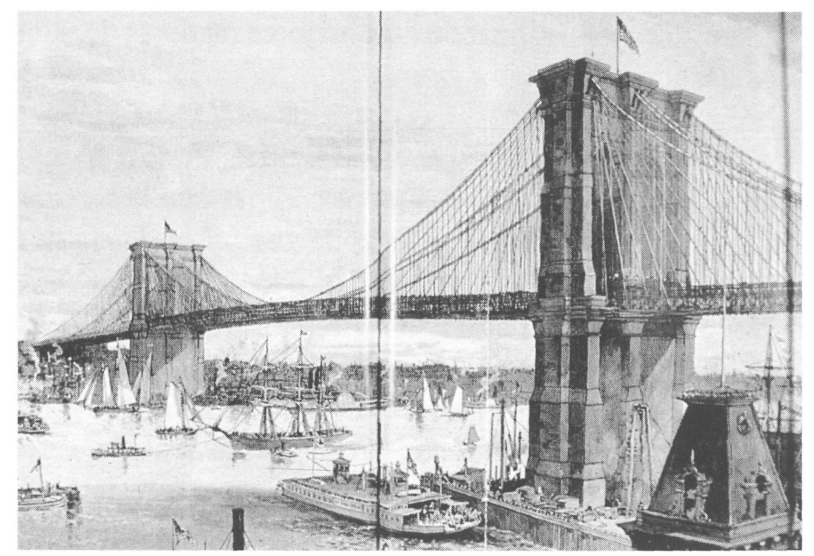

Figura 6. - Puente de Brooklyn en una imagen de la época de su construcción. 


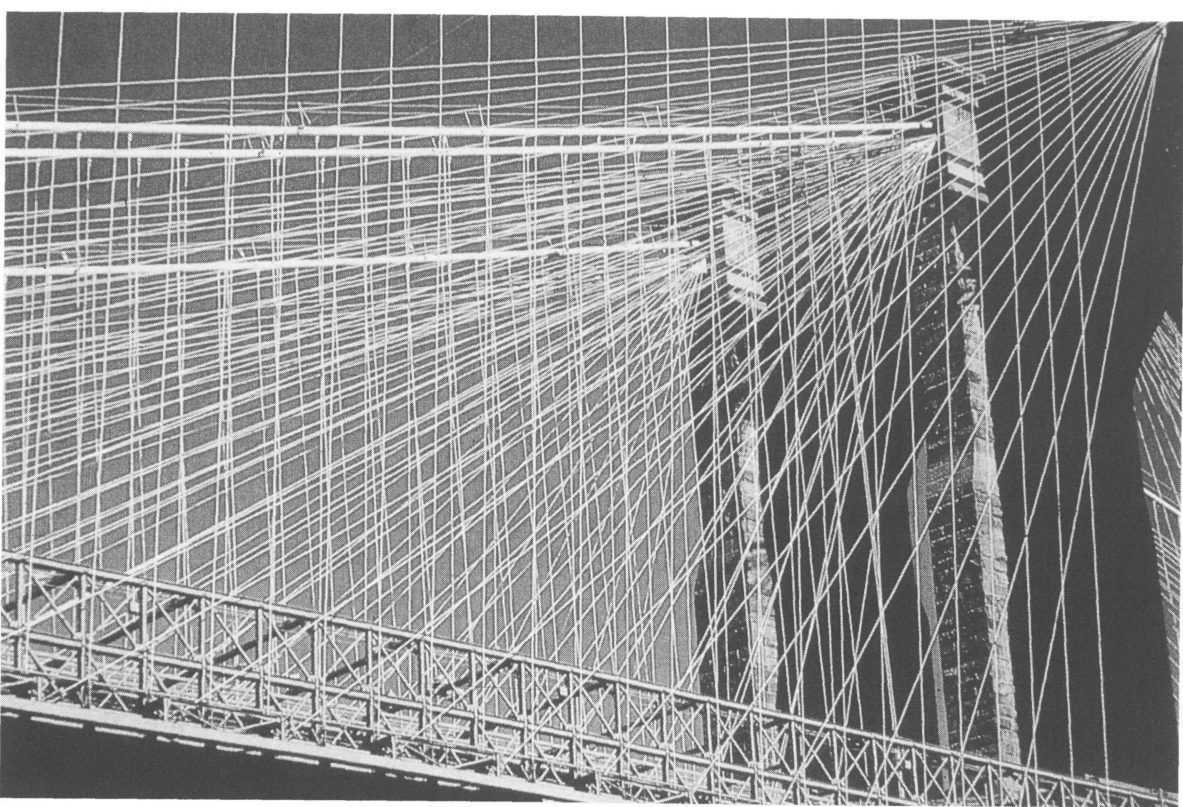

Figura 7.- Los tirantes inclinados -stays- del Puente de Brooklyn.

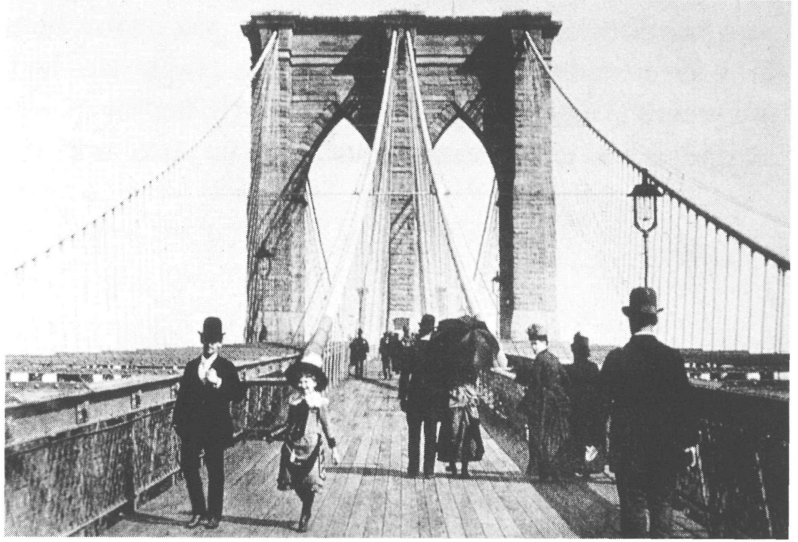

Figura 8.- Puente de Brooklyn. Paseo Peatonal (1883).

construye el extraordinario y magnífico paseo superior peatonal elevado sobre la calzada, donde Henry Miller subía "sólo en momentos de extrema angustia" encontrándose "colgado en el vacío"; todo le parecía allí "irreal, innecesario". Un paseo que, como profetizaba Roebling en su Memoria, "permitirá al pueblo en sus horas libres, a los viajeros y jóvenes inválidos, pasear sobre el puente en los días hermosos y disfrutar de las bellas vistas y el aire puro ... en una tumultuosa y atestada ciudad comercial, un paseo como éste será de un valor incalculable".

John Roebling murió en 1869 a consecuencia del tétanos producido por el aplastamiento de un pie por una barcaza, cuando planteaba la torre del lado de Brooklyn. Su hijo Washington, también ingeniero, graduado en América, culminó la obra de su padre, aunque a costa de quedar paralítico en 1872 a consecuencia de la terrible aeropatía, una enfermedad que se producía con cierta frecuencia

(c) Consejo Superior de Investigaciones Científicas Licencia Creative Commons 3.0 España (by-nc) cuando se trabajaba en el interior de los cajones neumáticos de cimentación. Dirigió las obras desde su casa en lo alto de una colina de Brooklyn, con la ayuda de unos prismáticos y de su mujer, que le servía de ayudante y correo para llevar a la obra las instrucciones y planos. Murió a los 90 años, en 1926, sin haberse montado nunca en un automóvil.

El puente de Brooklyn estableció las bases teóricas y la práctica de detalle, sin los que no hubieran sido posibles los grandes puentes colgantes del siglo XX; y cuando los ingenieros contemporáneos se olvidaron de alguno de estos principios de Roebling -como el de la rigidez-se llegó al desastre del puente de Tacoma en 1940, lo que obligó a reforzar la mayoría de los grandes puentes colgantes construidos hasta entonces.

El puente de Brooklyn ha sido objeto de atención durante un siglo por parte de innumerables intelectuales, pintores y poetas. Además de los ya citados, despertó la admiración y fue fuente de inspiración de los artistas más diversos, como por ejemplo Henry James, John Dos Pasos, Majakovsky, Joseph Stella o García Lorca. Como muestra, unos fragmentos del elogio del puente publicado por José Martí en 1883 en Nueva York: “¡Oh, broche digno de estas dos ciudades maravilladoras! ¡oh, guión de hierro, de estas dos palabras del Nuevo Evangelio!... Así han fabricado, y así queda, menos bella que grande, y como brazo poderoso de la mente humana, la magna estructura. Ya no se abren fosos hondos en torno de almenadas fortalezas; sino se abrazan con brazos de acero, las ciudades... los puentes son las fortalezas del mundo moderno. Mejor que abrir pechos es juntar ciudades. ¡Esto son llamados ahora a ser todos los hombres: soldados del puente!". 


\section{SEVILLA. EL PUENTE DEL CENTENARIO}

Lo primero que quiero decir es que esta obra es el resultado de una experiencia compartida con Julio Martínez Calzón en el proyecto y construcción de puentes a lo largo de nuestra vida profesional, que cuenta ya con treinta y cinco años; una experiencia que abarca no sólo los aspectos técnicos, sino también los conceptuales, históricos y estéticos. En este proyecto fue muy importante la colaboración de nuestros compañeros Francisco Millanes y Guillermo Ontañón.

El planteamiento y el trazado fueron muy laboriosos al estar sujetos a numerosos condicionantes, en especial, al Plan general municipal de ordenación, en curso simultáneo de formulación durante la redacción del proyecto del puente en 1986-87, así como a las necesidades del puerto, a la disponibilidad del suelo e instalaciones militares y a las previsiones de los trazados e instalaciones ferroviarias.

En su conjunto, el tramo suroeste de la autovía de circunvalación de Sevilla, de $6,5 \mathrm{~km}$ de longitud, -donde se inserta el Puente del Centenario- sirve a la doble función de proporcionar continuidad a las carreteras que inciden en la ciudad de Sevilla y de establecer una ronda urbana, muy útil para el tráfico local. Las conexiones múltiples con el puerto, a ambos lados de la dársena, y con la propia ciudad, o bien con Córdoba, Cádiz, Huelva y Extremadura, obligan a disponer cuatro nudos, dos a cada lado del río, con un conjunto en estos enlaces de 16 puentes, 27 ramales y 3 glorietas.

La elección de la solución adoptada para el trazado del puente está, pues, muy directamente relacionada con los antecedentes urbanísticos y administrativos que conducen de forma casi obligada a establecer un puente de gran longitud entre estribos que sobrepase las zonas de utilización portuaria, creando las mínimas molestias posibles en todos los sentidos. Esto requiere unas dimensiones apropiadas para las luces de los largos accesos al gran puente sobre la dársena del río $\mathrm{y}$, al mismo tiempo, la disposición de una gran estructura singular capaz de salvar la dársena del Guadalquivir de forma adecuada en gálibos y luces para no entorpecer la funcionalidad necesaria para la navegación. El Puente del Centenario propiamente dicho, lo constituye la estructura atirantada de $564 \mathrm{~m}$ de longitud entre juntas de dilatación, con un gran vano central de $265 \mathrm{~m}$ de luz y $60 \mathrm{~m}$ de altura de rasante sobre el río.

Sin olvidar el inevitable carácter emblemático que por sus enormes dimensiones este puente estaba destinado a adquirir y la elevada dignidad estética que exigía tan fuerte intervención en una ciudad y sobre un río tan ilustres, por razones éticas era necesario ajustarse a un coste estricto y,

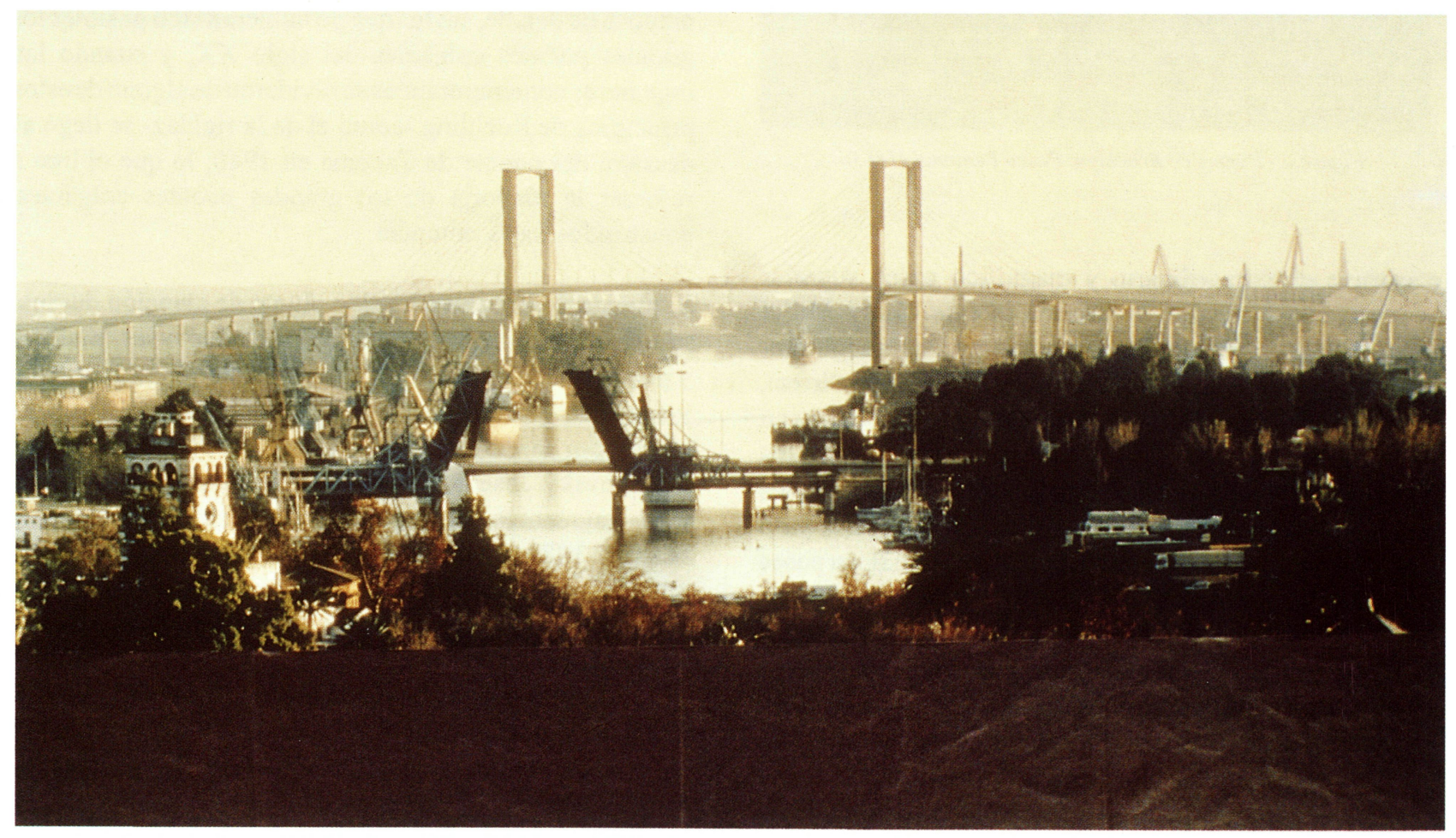

Figura 9.- El Puente del Centenario spbre la dársena del Guadalquivir, surgiendo entre las grúas del puerto. Delante, el desaparecido puente levadizo de Alfonso XIII. Como dice Chillida: "la vocación de este puente es corregir el radio de la Tierra". 
en consecuencia, a un sistema constructivo rápido y sencillo. Esta economía y sencillez constructivas han nacido paradójicamente de complejos procesos teóricos, desarrollados durante muchos años de investigaciones, cálculos y experiencias continuas en puentes anteriores.

El puente se asienta en dos conceptos técnico-históricos fundamentales en nuestro trabajo. En primer lugar, la superación en nuestra profesión de la antigua y arraigada división entre ingenieros metálicos e ingenieros hormigoneros; $y$, en segundo lugar, la prefabricación, es decir, la utilización de grandes elementos estructurales previamente esculpidos para ser sabia y ordenadamente engarzados in situ.

Si bien es verdad que los primeros ingenieros civiles, con Smeaton, Mylne, Rennie y Telford a la cabeza, trabajaron indistintamente con toda clase de materiales (madera, piedra y estructuras metálicas, ya fueran de hierro fundido o forjado), a mediados del siglo XIX surge la separación entre los ingenieros de fábricas y los ingenieros metáli$\cos$, aislamiento que se agudiza más con la aparición y extensión del hormigón armado, llegando entre ellos a competencias y rivalidades terribles. En efecto, ni Eiffel, Roebling o Ammann proyectaron puentes en piedra o en hormigón y, por el otro lado, ni Sejourné, Nervi, Maillart o Freyssinet lo hicieron con estructuras metálicas. Torroja es una excepción, aunque su mentalidad era mucho más de hormigonero que de metálico: para comprobarlo basta leer su famoso libro "Razón y Ser de los tipos estructurales".

Desde el comienzo de mi trabajo común con Julio Martínez Calzón, hemos venido intentando la superación de este maniqueismo histórico con el empleo de estructuras mixtas, donde la colocación de los diferentes materiales es nítida, tanto desde el punto de vista técnico como formal, como, por ejemplo, en el Paso Superior sobre la Castellana, entre las calles de Juan Bravo y Eduardo Dato, en Madrid, proyectado en 1968, primer puente donde se combina una estructura mixta en acero Corten y placas prefabricadas pretensadas

La importancia de la superación de esta dicotomía se entiende mejor con dos analogías históricas. En Roma se construye tradicionalmente con opus quadratum (sillares grandes de piedra regular bien labrada y concertada a hueso), opus testaceum (fábrica de ladrillo) y opus caementicium (masas de hormigón para cimientos). En un momento determinado, probablemente coincidente con la aparición de las grandes bóvedas y cúpulas a finales del siglo I d.c., aparece el opus latericium, es decir, una fábrica muy técnica que tiene un núcleo de hormigón y un encofrado de ladrillo incorporado estructuralmente al hormigón y que trabaja de modo mixto, con el que se construyen los grandes edificios de vanguardia técnica de la Roma Imperial. Se trata, evidentemente, de una fábrica mixta en cuanto a los materiales, de gran importancia constructiva, ya que evita las enormes cimbras y encofrados utilizados con anterioridad, reduciéndolas a simples sopandas y, por otro lado, de gran importancia estética, porque permite la combinación de colores, alternando más tarde los ladrillos con la piedra y con las cabezas de las pequeñas pirámides del opus reticulatum.

Las consecuencias de esta innovación romana se extienden hasta la mezquita de Córdoba, pero sus enseñanzas técnicas fueron olvidadas al tiempo que se olvidaba también la fabricación del hormigón en la Edad Media. Se trata, pues, de una tradición romana que solamente recogieron los musulmanes andaluces, pero limitada a un sentimiento estético, sin entender la capacidad técnica de la mezcla de ambos materiales, a pesar de la claridad con que esta manera de entender las estructuras estaba expresada, tan cerca como en el propio acueducto de los Milagros de Mérida.

El planteamiento de fusión de los dos materiales, hormigón y acero, y la superación de esta dicotomía histórica que nosotros intentamos en las grandes pilas de este puente atirantado de Sevilla son, pues, análogos a los que en Roma se alcanzan, en su momento cumbre constructivo, con la utilización del ladrillo y el hormigón. Se trata de un entendimiento total, no diferenciado, sino absoluto y engranado en un mutuo trabajo, con consecuencias técnicas en el proyecto, en el cálculo, en el proceso constructivo y en las formas estéticas finales.

Otro ejemplo paradigmático en esta dirección es el acueducto Pont Cyssylte en el valle de Llangollen sobre el río Dee(1795-1805), proyectado por Thomas Telford, quizá la más clásica de todas sus obras, donde el hierro fundido de los tableros y la piedra de las pilas aparecen cada uno en su lugar, pero trabados, escuchándose juntos, trabajando en lo suyo, armoniosamente, como en la música de Bach, "una combinación transparente de voces independientes, cada una de las cuales puede ser reconocida".

Pero nuestro puente no tiene solamente una fuente primigenia, sino además otra también esencial: la prefabricación. Un concepto rico y complejo que nosotros entendemos, no sólo como un sistema constructivo de formas ya establecidas previamente que son despiezadas por estrictas razones económicas, sino como un proceso profundo que, en sí mismo, define formas y límites, y además como un modo de entender la construcción y su expresión formal. Se trata de grandes bloques de $60 \mathrm{t}$ con juntas secas, con superficies finales excavadas, nunca añadidas, lo que configura un tablero de enormes piezas pretensadas organizadas con un orden, al modo de un gigantesco arquitrabe griego de $22 \mathrm{~m}$ de anchura colgado a lo largo de $456 \mathrm{~m}$ sin interrupción alguna, de modo que no se produce apoyo del tablero en los travesaños de las pilas altas, sino que permanece suspendido exclusivamente por los tirantes. 


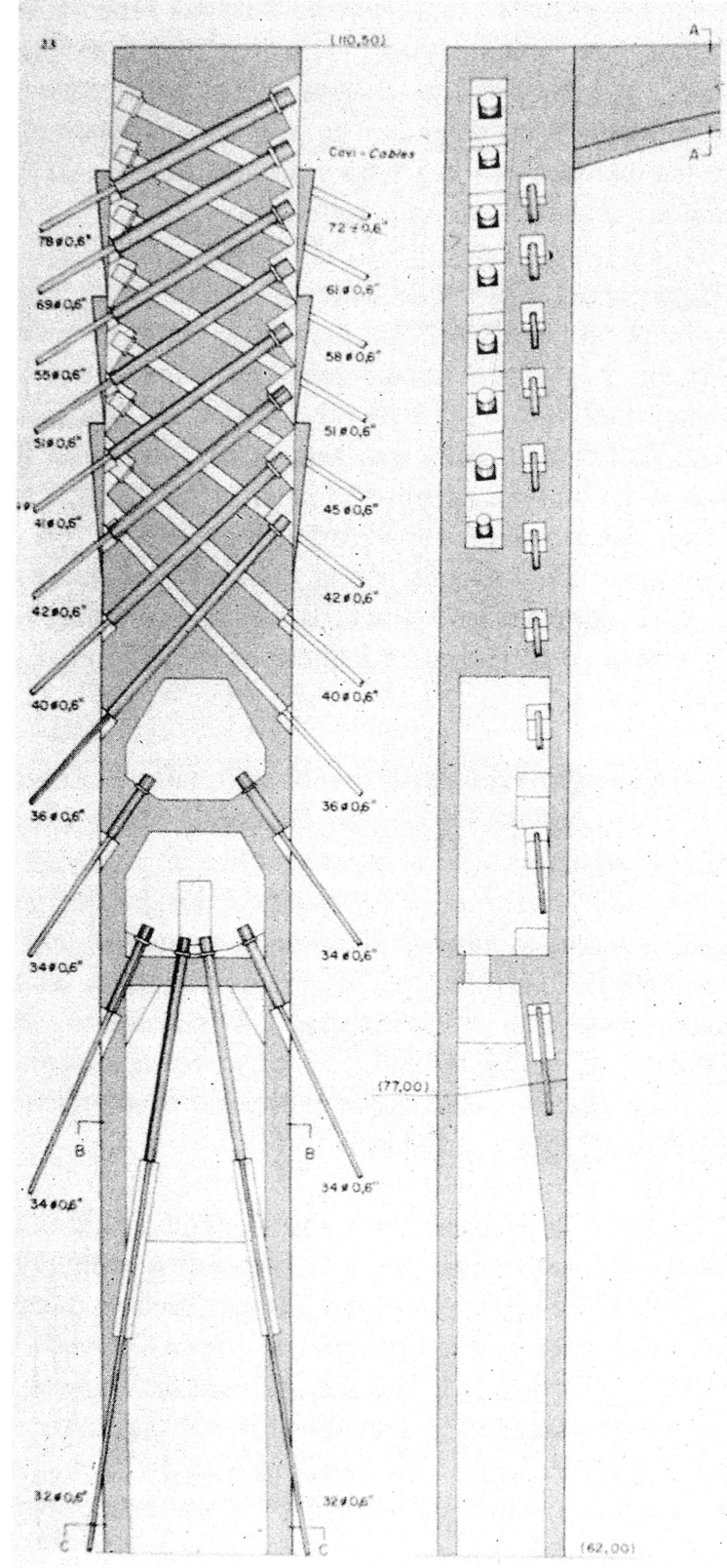

Figura 10.- Puente del Centenario. Cabeza de pilas mixtas con los anclajes de los tirantes.

La prefabricación es, en la construcción, un símbolo moral. De ahí su directa relación con la belleza. Porque, como dice Eugenio Trías, "la belleza o es símbolo moral o es pura ornamentación que sólo sirve de ornato y legitimación del poder". Y así lo entendieron no sólo los constructores clásicos, sino todos aquéllos que impulsaron la construcción con una más profunda y lúcida utilización de los materiales y los procesos, no sólo por razones económicas, sino porque arrancaban desde un punto de partida cuya raíz es ética. Juan de Herrera en El Escorial, Eiffel en sus grandes estructuras metálicas, Telford con su obsesión por las grandes piezas -en contra de la opinión de sus contemporáneos- o Freyssinet en los puentes de Marne, pueden ser ejemplos incontestables del contenido ético que

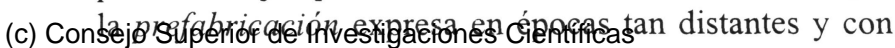
Licencia Creative Commons 3.0 España (by-nc) diferentes materiales y maquinarias, pero con una condición común.

Se trata de una tradición de prefabricados en la que estamos inmersos desde que tenemos uso de razón como ingenieros, entendida como un proceso ético, técnico y estético y no como un problema de despiece y acumulación de masas, cuya piel luego se decora y se enmascara a la moda del momento. Por el contrario, esta manera de entender las estructuras prefabricadas permite proyectarlas y construirlas como algo que encaje los embates del tiempo, es decir, la acción implacable de la vibradora universal que termina sin remedio con los añadidos cambiantes, dejando al descubierto lo verdadero.

Los tirantes se anclan en el tablero a intervalos de $12 \mathrm{~m}$, mientras que en las pilas lo hacen buscando la máxima altura posible, pero manteniendo la condición de que en cada punto de anclaje sólo se cruzan dos tirantes, uno por cada lado de la pila. La estabilidad longitudinal está exclusivamente conseguida por las pilas principales, que actúan como grandes ménsulas que recogen las acciones de los tirantes.

La inserción de los anclajes en las zonas superiores de los fustes de las pilas provocan la aparición de líneas quebradas y vibraciones, sensación acentuada por la concentración de los tirantes blancos, alcanzándose, así, en lo más alto, la síntesis de toda la potencia y ligereza del puente, el foco de su complejidad estructural y su sencillez constructiva, y, al mismo tiempo, el símbolo de su funcionalidad y belleza.

Unas palabras de Brancusi encabezan el proyecto: "la simplicité n'est pas un but dans l'art, mais on arrive à la simplicité malgré soi en s'approchant du sens réel des choses". Ante la confusión de formas, tipologías, imágenes y materiales usados y abusados en nuestros días, el objetivo de este proyecto es alcanzar lo simple, es decir, enfrentar a lo desmedido la medida y liberar de la confusión lo simple: ésta es la ley más íntima del puente del Centenario.

Su concepto no es un concepto general, válido para todos los puentes, no es imitable, porque tal universal sería lo indiferente al lugar y al tamaño: por el contrario, está más cerca de esa esencia, que sólo aparece en los casos especiales. La paradoja es que esta esencia, enraizada e histórica, se constituye con elementos de nuestro tiempo: lo industrial, la prefabricación, las estructuras mixtas, los grandes tirantes..., y no con referencias históricas formales. Lo fundamental es el orden en que se han dispuesto los materiales y su conexión interna. No es, pues, un problema de formas, sino de estructura, de materiales y de funciones.

Chillida, con su extraordinaria capacidad poética para llegar a lo esencial, definió así el Puente del Centenario: "la vocación de este puente es corregir el radio de la Tierra". http://informesdelaconstruccion.revistas.csic.es 


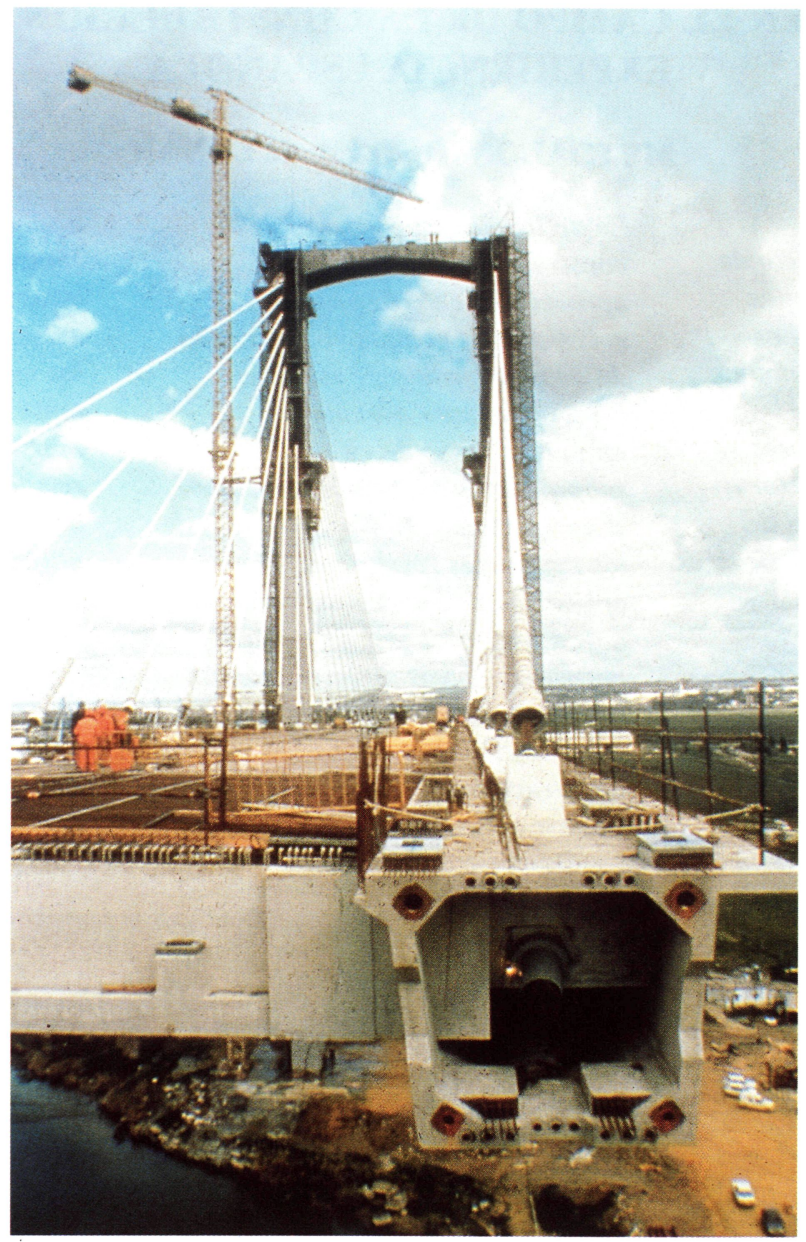

Figura 11.- Puente del Centenario. Frente de avance del tablero con las piezas prefabricadas.

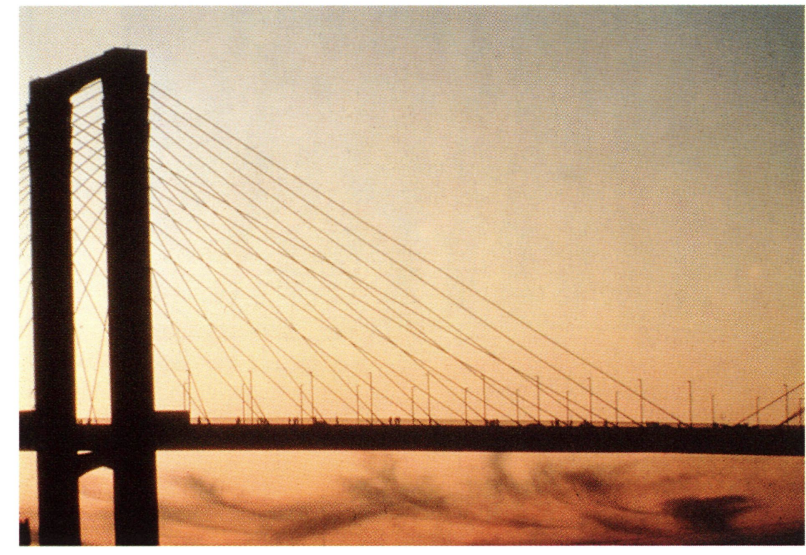

Figura 12.- Atardecer en el Puente del Centenario.

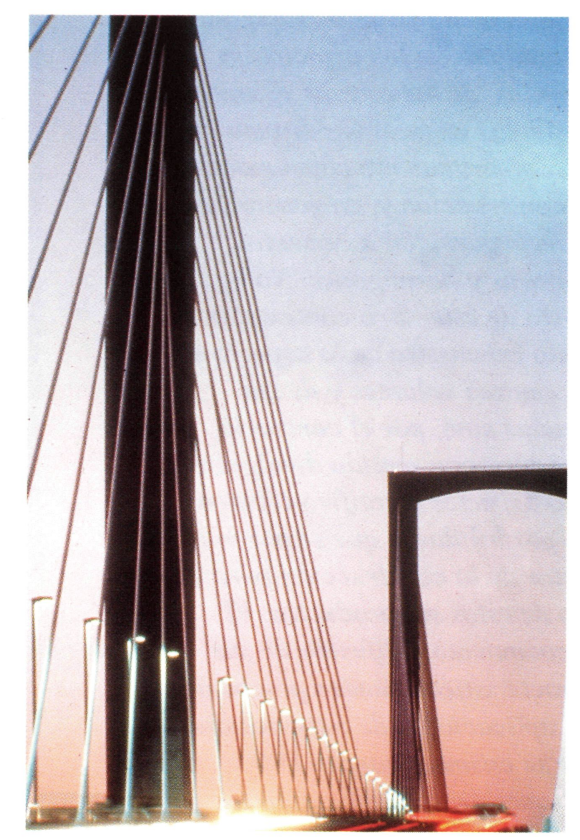

Figura 13.- Visión nocturna del Puente del Centenario. 